\title{
INNOVATIVE RECYCLING OF END OF LIFE SILICON PV PANELS: RESIELP
}

\author{
Pietrogiovanni Cerchier ${ }^{1, \star}$, Katya Brunelli ${ }^{1}$, Luca Pezzato ${ }^{1}$, Claire Audoin ${ }^{2}$, Jean Patrice \\ Rakotoniaina ${ }^{2}$, Teresa Sessa ${ }^{3}$, Marco Tammaro ${ }^{4}$, Gianpaolo Sabia ${ }^{5}$, Agnese Attanasio ${ }^{6}$, \\ Chiara Forte ${ }^{7}$, Alessio Nisi ${ }^{7}$, Harald Suitner ${ }^{8}$ and Manuele Dabalà ${ }^{1}$ \\ ${ }^{1}$ Department of Industrial Engineering, University of Padova, via Marzolo 9, 35131, Italy \\ 2 University Grenoble Alpes, CEA, Liten, Campus Ines, 73375 Le Bourget du Lac, France \\ ${ }^{3}$ Relight, via Lainate 98/100, 20017 Rho, Italy \\ ${ }^{4}$ ENEA, Energy and Sustainable Economic Development, Division Resource Efficiency, Piazzale E. Fermi 1, 80055, Naples, Italy \\ ${ }^{5}$ ENEA, Energy and Sustainable Economic Development, Division Resource Efficiency, via M.M. Sole 4, 40129 Bologna, Italy \\ ${ }^{6}$ CETMA, Diagnistic and Civil Engineering Area, Advanced Materials \& Processes Consulting Division, s.s. 7 Appia, 72100 Brindisi, Italy \\ ${ }^{7}$ I.T.O. S.r.I., via Achille Costa 60, 73044 Galatone, Italy \\ ${ }^{8}$ PROJEKTkompetenz.eu GmbH, Franz-Josef-Str. 19/7, 5020 Salzsburg, Austria
}

Article Info:

Received:

30 September 2020

Revised:

16 April 2021

Accepted:

23 June 2021

Available online:

30 September 2021

Keywords:

PV panels recycling

Silicon

Glass

End of Life PV panels

Recycling

\section{ABSTRACT}

In Europe, an increasing amount of End of Life (EoL) photovoltaic silicon (PV) panels is expected to be collected in the next 20 years. The silicon PV modules represent a new type of electronic waste that shows challenges and opportunities. ReSiELP was a European project that aimed at recovery of valuable materials (aluminum, glass, copper, silicon, and silver) from EoL silicon PV modules. During the project a pilot plant, constituted by a furnace, a gas abatement system, an apparatus for the mechanical separation and a hydrometallurgical plant was designed and built. The pilot plan was realized to upscale recycling technology to TRL 7, with a 1500 panels/ year capacity. The feasibility of industrial-scale recovery and the reintegration of all recovered materials in their appropriate value chain was investigated. The results obtained showed that $2 \mathrm{~N}$ purity silicon and $2 \mathrm{~N}$ purity silver can be recovered with high efficiency. In order to realize a zero-waste plant, a hydrometallurgical process was developed for the wastewater treatment. Moreover, the use of recovered glass for building materials was investigated and the obtained performance seemed comparable with commercial products.

\section{INTRODUCTION}

Millions of photovoltaic (PV) panels have been installed worldwide over the past three decades, and, considering an estimated lifetime between 20 to 30 years, more than $2 \mathrm{M}$ tons of End-of-Life (EoL) PV panels are expected to be collected in next 15 years. Once the modules reach their end-of lifetime, they are considered waste and in Figure 1 is shown the estimate amount of this waste in Europe for the next years, considering 20 years as average time gap from installation to disposal (Jager-Waldau, 2017). A report published by the International Energy Agency Photovoltaic Power Systems Programme (IEA PVPS) and the International Renewable Energy Agency (IRENA) in 2016 has forecast that PV modules waste globally will amount to 1.7-8.0 million tons cumulatively by 2030 and to $60-78$ million tons cumulatively by 2050 (IRENA and IEA-PVPS, 2016).
This enormous amount of EoL Silicon (PV) modules would require the implementation of a circular value chain to ensure a secure supply of raw materials and to limit disposal in landfill (Choi \& Fthenakis, 2010). Silicon metal has been considering a critical raw material by European Commission since 2014 (European Commission, 2015), and, therefore, it would be crucial to recover it from EoL PV panels. Moreover, silicon production needs intensive energy consumption whereas its recovery reduce the energy consumption (Müller, Wambach, \& Alsema, 2006), thus making its recycling advantageous to the environment.

According to European Commission, $85 \%$ of the solar panels currently manufactured are based on crystalline silicon (c-Si) technologies (Dias, Benevit, \& Veit, 2016; Paiano, 2015). A typical c-Si PV panel today is approximately composed by : 76 wt\% glass, 10 wt\% polymer, 8 wt $\%$ aluminum, $5 \mathrm{wt} \%$ silicon, $1 \mathrm{wt} \%$ copper, less than 0.1 


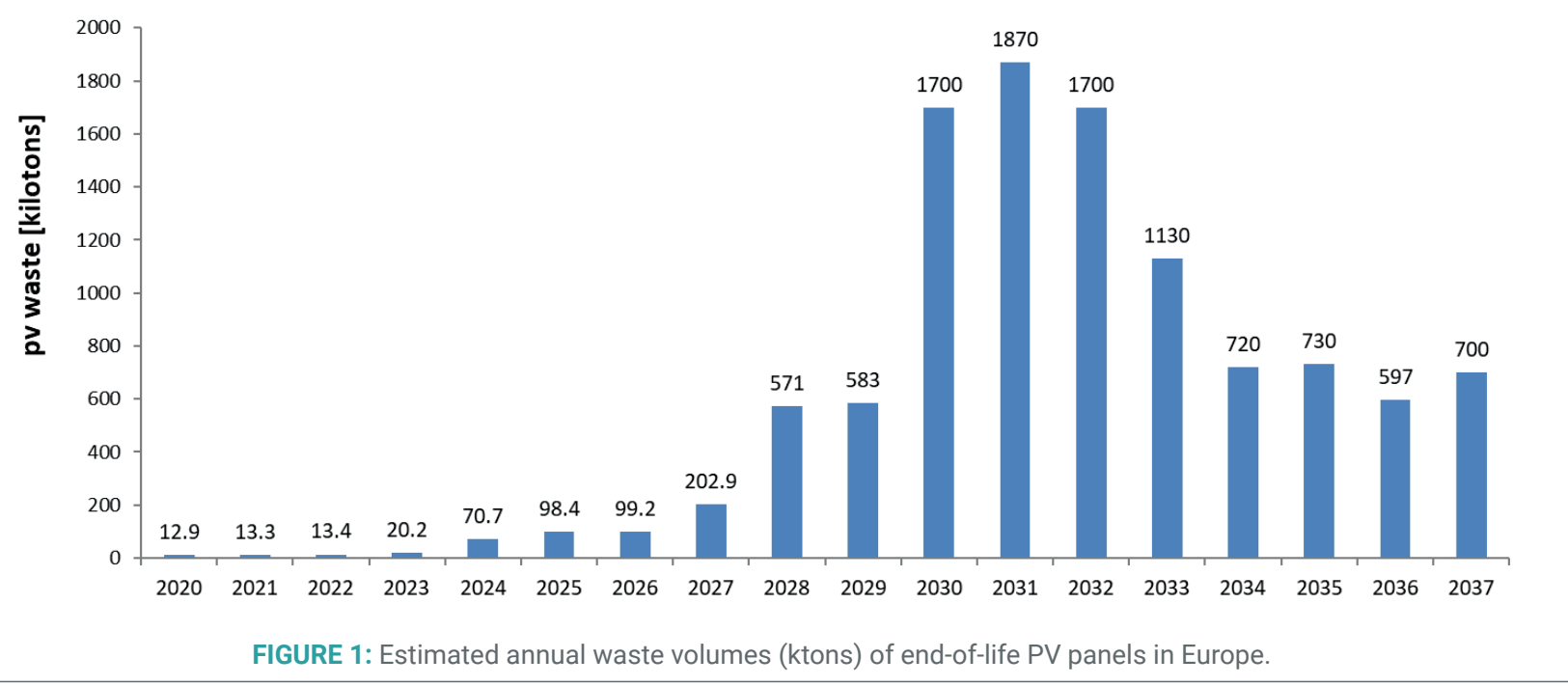

wt\% silver, and tin and lead (Weckend, Wade, \& Heath, 2017). End-of-life solar PV panel management is a newly emerging field that needs further research and development (Xu, Li, Tan, Peters, \& Yang, 2018). As a matter of fact, despite the richness of EoL panels in valuable materials, only one industrial plant currently exists in Europe for dismantling and recycling of EoL PV panels and it is based on mechanical treatments.

ReSiELP (www.resielp.eu), a European project supported by EIT RawMaterials from 2017 to 2020, involved several partners (universities, research institutes and SME's) from different European countries. ReSiELP aimed at recovering from EoL PV panels, other than aluminum, glass and copper, also the others valuable materials such as silicon and silver using a thermo-mechanical-hydrometallurgical process, and at implementing a zero-waste innovative recycling loop (Sgarioto, et al., 2018). ReSiELP proposed a circular economy with a product centric zero-waste approach, as shown in Figure 2. The project was mainly focused on the development of a recovery and purification process to obtain Si with such purity as to be reused as raw material in the PV production. The process included also the recovery of glass, copper and silver to allow their reintegration in their value chain. Moreover, the use of recovered glass as building material was investigated. In order to minimize the environmental impact of the recycling plant and to realize

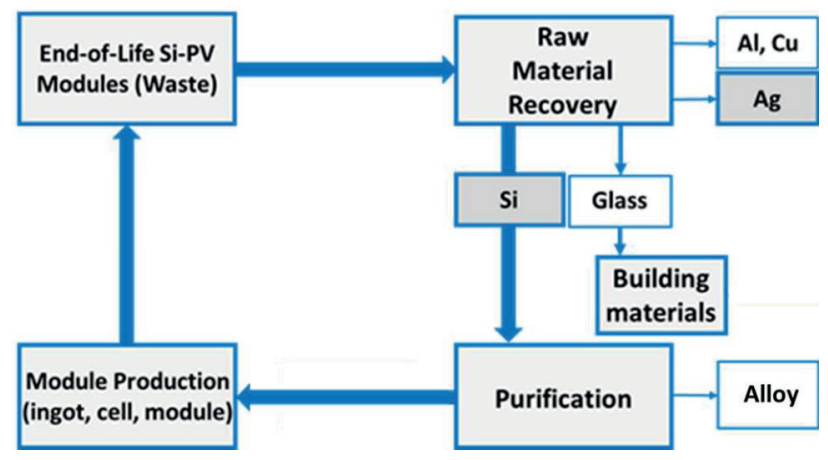

FIGURE 2: ReSiELP concept. a zero-waste process, a treatment for the wastewater coming from the process was studied

\section{RESIELP PROJECT OVERVIEW}

\subsection{The recovery process}

The thermo-mechanical-hydrometallurgical process for the recycling of EoL PV panels, developed at TRL 5 by the group of metallurgy of Padova University, was upscaled at pilot plant (technology readiness level TRL7). The group of metallurgy of Padova University designed and built the new plant, that was installed at Relight company located in Rho (Milan). In detail, were designed and built the furnace, the gas abatement system, the apparatus for the mechanical separation and the hydrometallurgical plant (Figure 3).

The recycling process is shown in Figure 4 and was composed of four parts:

1. Dismantling and cutting;

2. Heating treatment;

3. Material separation;

4. Chemical treatments;

5. Silver recovery.

In the plant, the aluminum frames and the power optimizers were first manually removed from the collected panels. The panels were then cut in half and one half-panel per batch was put in the furnace and treated at $450^{\circ} \div 550^{\circ} \mathrm{C}$ for $20 \div 30$ minutes to burn the polymeric part of encapsulant and backsheet.

The heating treatment was followed by the separation of the materials to divide Si cells from glass and copper ribbons. This step was performed with an apparatus built by the University of Padova and exploiting a patented process. The Si PV cells were chemically treated in the hydrometallurgical plant to remove aluminum paste, using a basic solution of sodium hydroxide, and silver contacts using a nitric acid solution. To verify the efficiency of the hydrometallurgical treatments, silicon cells were investigated by SEM (Cambridge Stereoscan 440) equipped with EDS.

The silver was recovered from the acid solution by a hydro-pyro metallurgical process. 

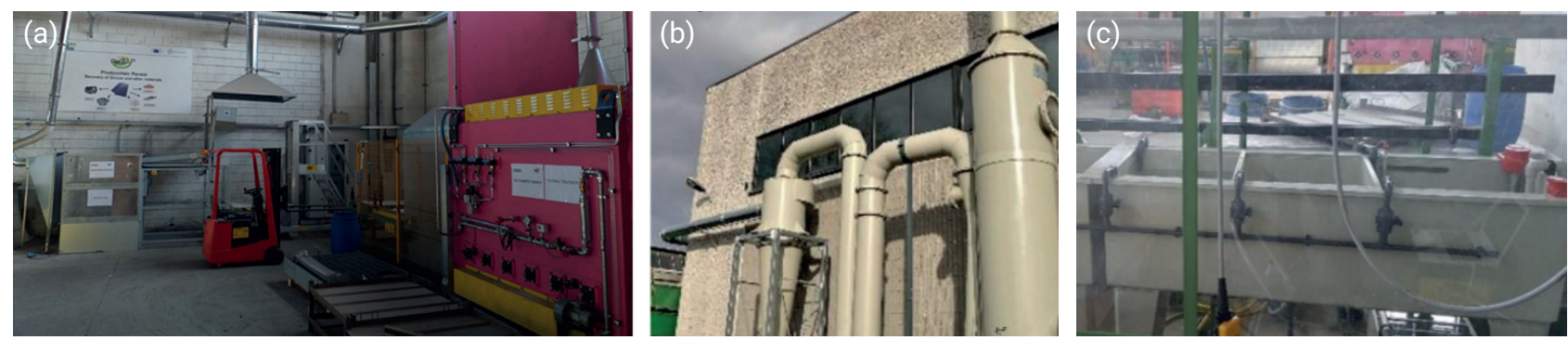

FIGURE 3: Images of pilot plant for the recycling process: a) furnace and separation system; b) gas abatement system; c) hydrometallurgical plant.

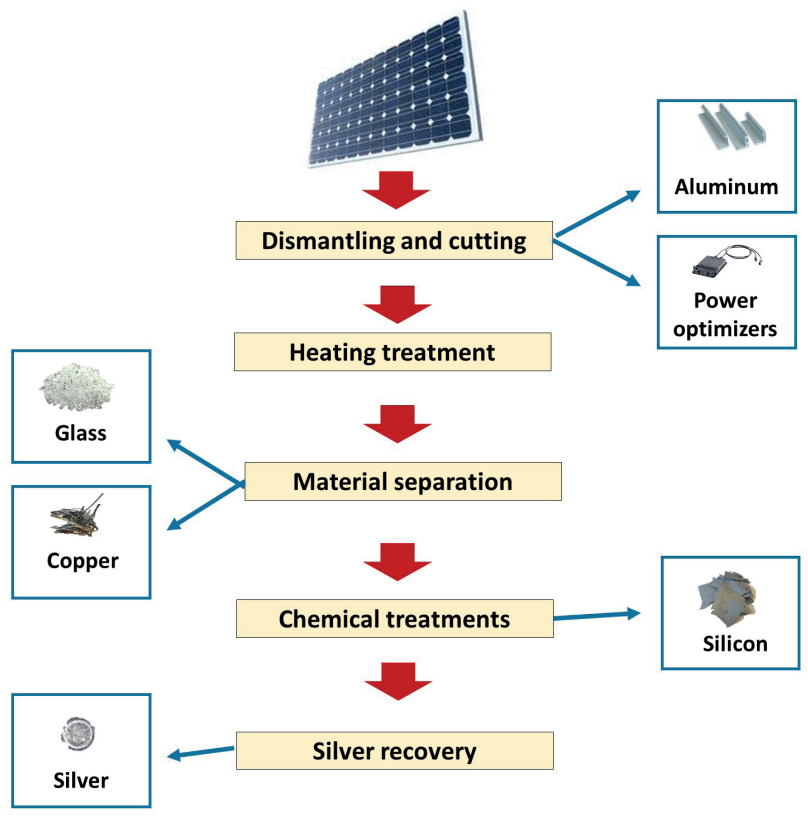

FIGURE 4: Estimated annual waste volumes (ktons) of end-of-life PV panels in Europe.

The recovered silicon and silver were finally analyzed with by a Spectro GENESIS inductively coupled plasma (ICP) mass spectrometer to determine the purity.

\subsection{The wastewater treatment}

ENEA studied a process to treat the wastewater coming from the hydrometallurgical plant to reduce the environmental impact of the process and to obtain a zero-waste approach.

The hydrometallurgical treatment for the recovery of metals from PV cells produced three main types of wastewater:

1. Acid wastewater;

2. Basic wastewater;

3. Washing wastewater.

Laboratory tests to identify the optimal conditions for the pollutants removal were carried out. For these experiments the more polluted basic and acid liquid streams were considered. The scope was to test conventional treatment technique in order to recover the water. The idea was making basic and acid wastewater react together in order to precipitate the metals contained in the solutions.

The first tests were carried out on alkaline hydrometallurgical wastewater by precipitation obtained varying the $\mathrm{pH}$. In the preliminary set of tests, reported hereafter, the analysis was performed on the alkaline solution. Such stream was sampled and settled and total solid concentrations were determined for the mixed solution and the supernatant after settling. For such analytical determination the supernatant was filtered with a Whatman glass microfiber filter GFC $(1,2 \mu \mathrm{m})$.

The supernatant was then treated dosing acid solutions in order to change the $\mathrm{pH}$ and promote precipitation process. Both $\mathrm{H}_{2} \mathrm{SO}_{4}(1.8 \mathrm{M})$ and $\mathrm{HCl}(1.16 \mathrm{M})$ acid solutions were separately tested: these laboratory-made solutions were slow dropwise added to $100 \mathrm{~mL}$ sample of basic wastewater.

These tests made it possible to identify the optimal $\mathrm{pH}$ corresponding the best metal removal efficiency. The removal rates achieved at the different reached $\mathrm{pH}$ were determined taking some amounts of the supernatant and using an ICP-MS instrument (Perkin-Elmer Sciex Elan 6000 ICP-MS).

According to lab tests, equipment dedicated to the recycling of wastewater was installed in the pilot plant.

\subsection{Innovative glass application}

The construction sector is constantly required to become more sustainable, for instance in terms of raw materials consumption. The valorisation of recycled materials, as partial replacement of conventional materials commonly used in construction materials, is a promising way to reduce consumption of natural materials and depletion of resources. The use of glass fractions, recovered from EoL PV-panels, is a sustainable option that can be implemented into building materials and the development of precast building components. Some works up to TRL 5 were carried out using recycled glass of different origin for building materials development (Tamanna, Mohamed Sutan, Lee, \& Yakub, 2013; Korjakins, Shakhmenko, Bajare, \& Bumanis, 2012). However, to the best of our knowledge, building materials incorporating recycled glass from PV-panels have not been produced on industrial scale so far. In ReSiELP project, CETMA and ITO worked together for the valorization of glass from PV-panels recycling which was re-used for the development of sustainable building materials (e.g. mortars, concretes) and precast components. This recy- 
cled material, after a mechanical treatment to be available in different sizes, was investigated as partial replacement of conventional aggregates, fillers and/or cements used for mortars/concretes/precast components production. Materials formulations were designed with the aim to maximize reused glass fractions taking into consideration the requirements of specific building applications (e.g. masonry mortars, concretes for prefabrication). The most promising concrete formulations were implemented at industrial scale with the production of precast components, thus demonstrating the potential of the developed solutions in operational environment (TRL7). Some prototypes of prefabricated slabs were produced in ITO industrial plants as demonstrators of the Project. The process as well as the equipment used for the production of these innovative building materials are conventional: this represents an important advantage of the investigated solutions.

\section{RESULTS AND DISCUSSION}

\subsection{The recovery process}

EoL PV panels were collected by Relight and treated according to the process developed by University of Padova.

After collection of EoL PV panels, the aluminum frame and the power optimizer were manually removed and each panel was cut in half. The half-panels without the aluminum the power optimizer are showed in Figure 5.

Several tests were performed to optimize the heating treatment parameters at industrial scale and were found the optimal temperature and time to induce the complete burning of the polymeric fraction (Figure 6). In comparison with mechanical and chemical treatments, this heating treatment prevented damages to the fragile Si cells, thus allowing an efficient recovery of materials. In fact, the Si cells, even if they got broken during the dismounting of PV panels and collection, were recovered in pieces with a me-

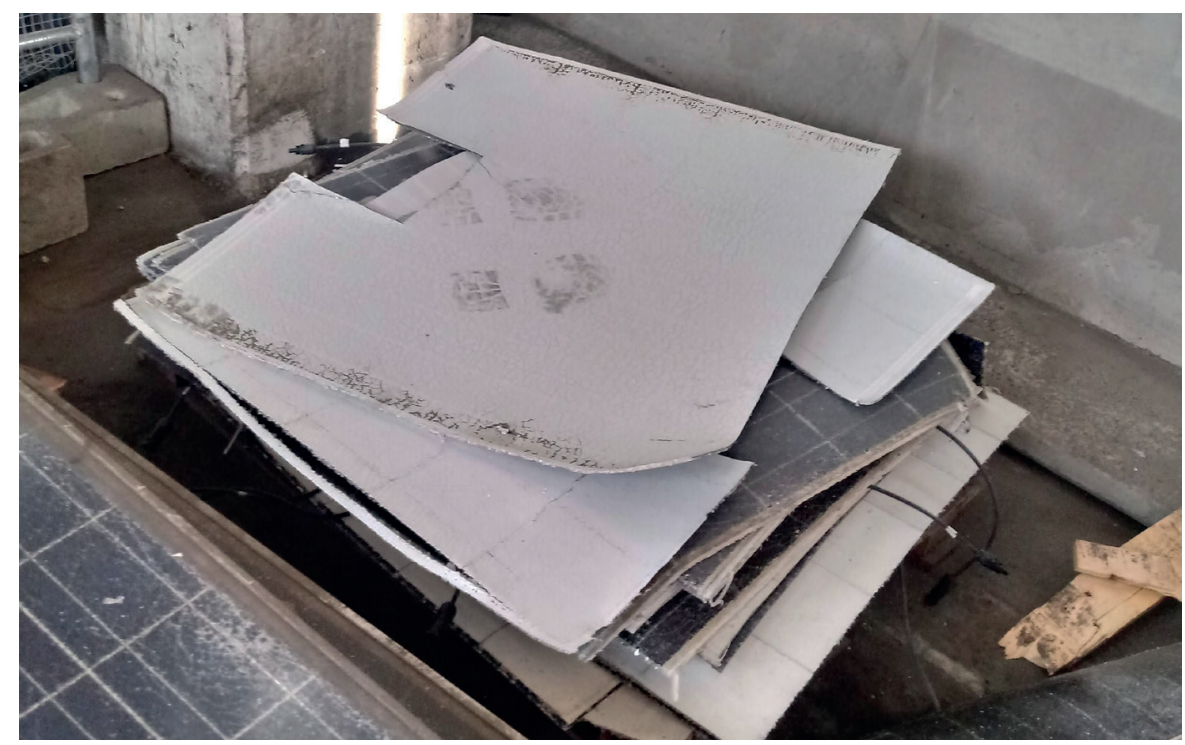

FIGURE 5: Example of PV halve panels prepared for heating treatment.

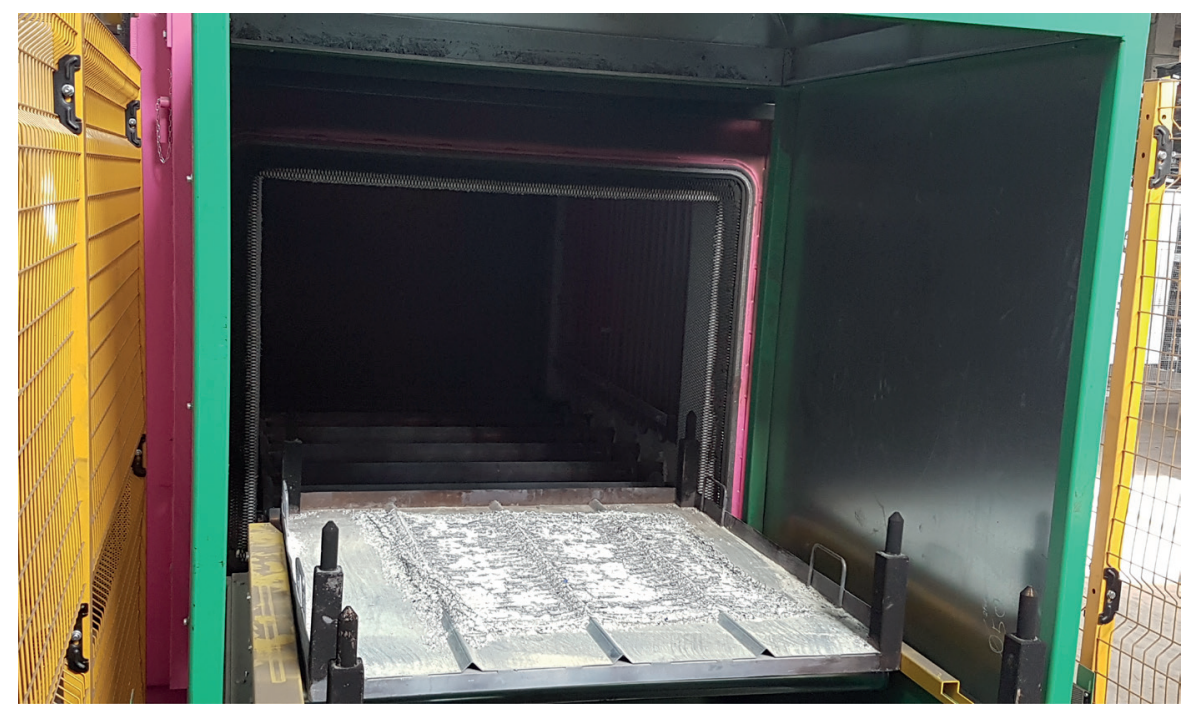

FIGURE 6: EoL PV panel after heat treatment in ReSiELP furnace. 
dium size of $5 \mathrm{~cm}^{2}$, whereas mechanical treatments used in the other plants reduce them in very thin powder. This size facilitated the separation and hydrometallurgical treatment.

All recovered materials are shown in Figure 7. With manual disassembly was possible to recover the $100 \%$ of aluminum frames (Figure 7b), whereas the separation system allowed the recovery of $98 \%$ of copper ribbons and glass (Figure 7c,f). $60 \%$ of silicon cells were suitable for hydrometallurgical treatment whereas a fraction was represented by glass and silicon powder that was not possible to separate.

The hydrometallurgical treatment of the Si PV cells, after the optimization of the process parameters, allowed the recovery of demetallized Si-cells using basic and acid solutions to remove aluminum paste and silver contacts, respectively (Figure 8). The process allowed recovering silicon cells with $2 \mathrm{~N}$ purity (Figure $7 \mathrm{~d}$ ). The silver was subsequently recovered from the acid solution of treatment with a hydro-pyrometallurgical process (Figure 7e).

In conclusion, the reliability of recovery plant processes has reached a high operating level (TRL7, as planned) with a capacity of 1500 panels/year. During the project 10 tons of EoL PV panels was treated to produce: $140 \mathrm{~kg}$ of silicon (Si-cells based) with $2 \mathrm{~N}$ purity, $2 \mathrm{~kg}$ of silver with $2 \mathrm{~N}$ purity, $6980 \mathrm{~kg}$ of glass with high purity, $1790 \mathrm{~kg}$ of aluminum frames and $88 \mathrm{~kg}$ of copper ribbons. Copper ribbon, aluminum frame and silver have been sold during the project. Silicon needed a purification in order to be reused in PV value chain.

\subsection{The wastewater treatment}

The basic wastewater contains mainly Al derived from the backsheet of silicon cells. In the laboratory test on the basic wastewater, the initial $\mathrm{pH}$ was $\approx 13.8$ and was lowered below 3 . Independently on the acid solution used $(\mathrm{HCl}$ or $\mathrm{H}_{2} \mathrm{SO}_{4}$ ), the formation of a suspension was observed for a $\mathrm{pH}$ value of about 13, while at $\mathrm{pH}$ around 3 a complete solubilization of the precipitated materials took place probably due to amphoteric characteristics. The analysis of the wastewater before and after the treatment is reported in Table 1.

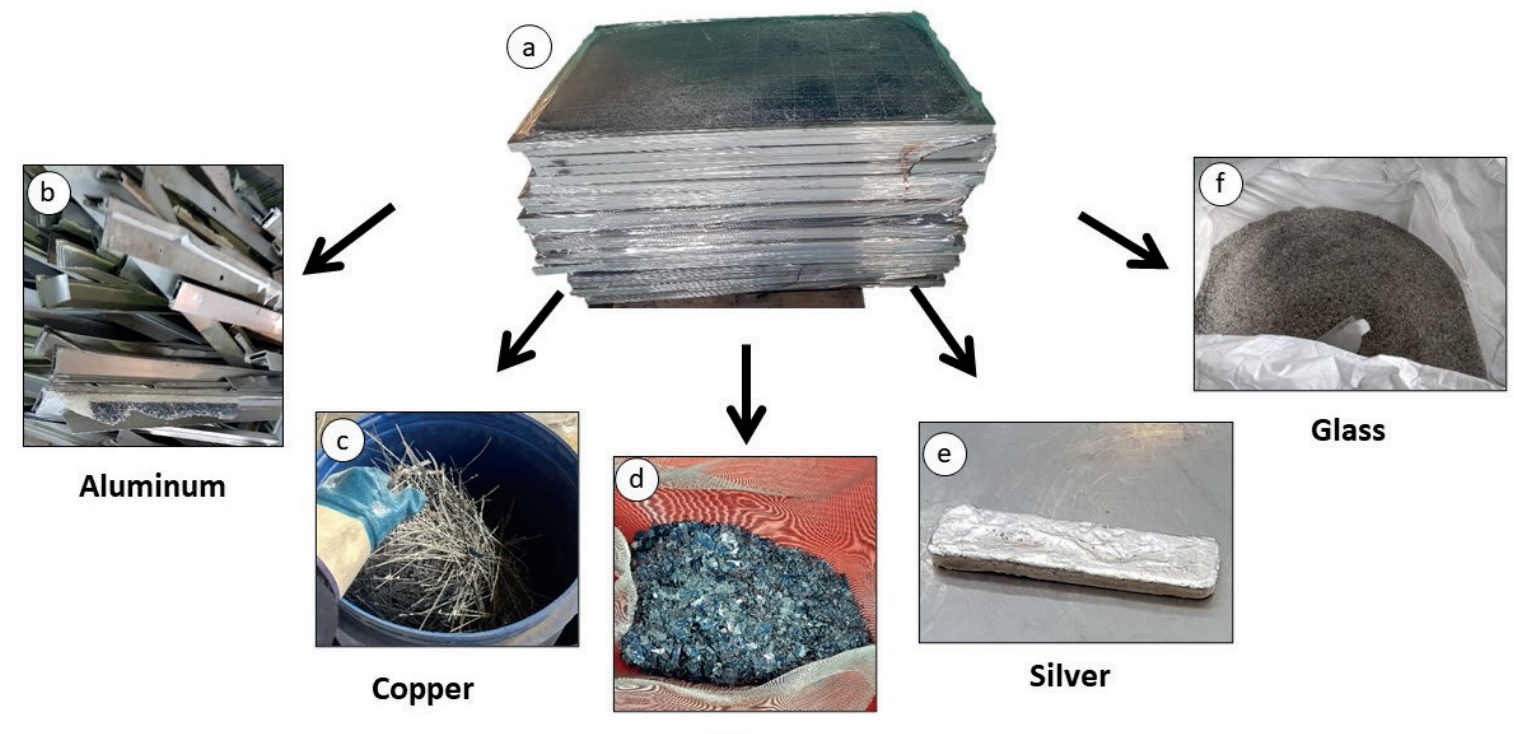

Silicon

FIGURE 7: PV waste (a) and materials recovered by ReSiELP pilot plant (b, c, d, e, f).
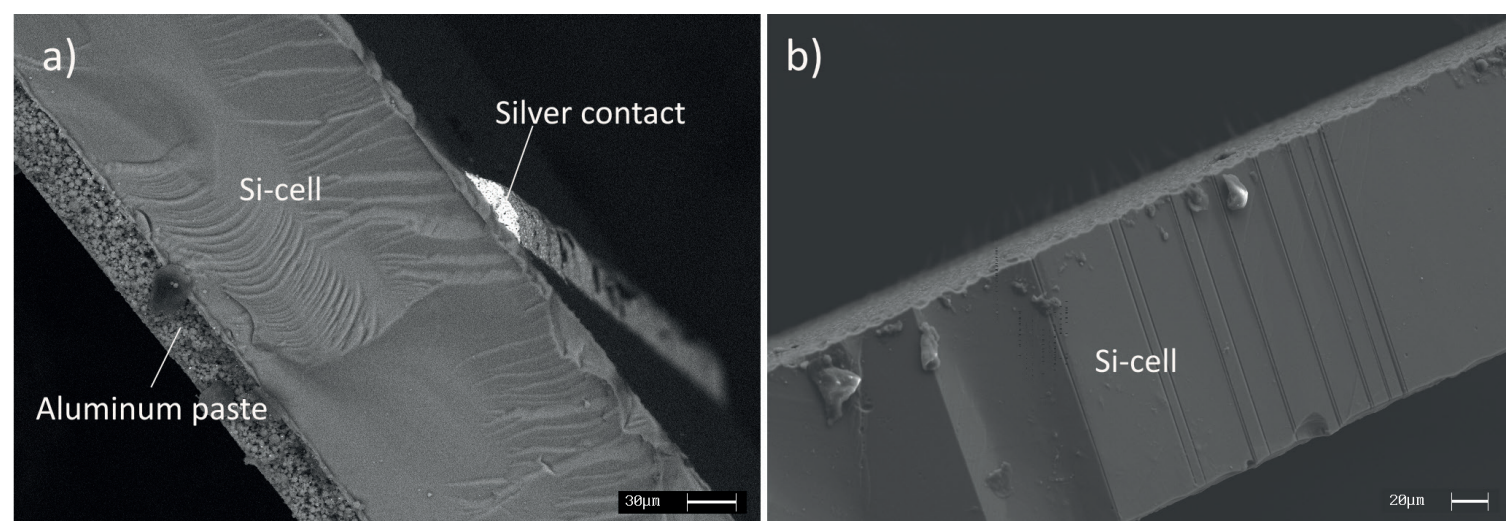

FIGURE 8: SEM images of silicon cell before (a) and after (b) the hydrometallurgical treatment. 
TABLE 1: Concentration of contaminants in basic wastewater before and after neutralization with $\mathrm{H} 2 \mathrm{SO} 4$ at pH 7.

\begin{tabular}{|c|c|c|c|}
\hline Contaminant & $\begin{array}{l}\text { Concentration [ppm] before } \\
\text { neutralization }(\mathrm{pH} 13.1)\end{array}$ & $\begin{array}{l}\text { Concentration [ppm] after } \\
\text { neutralization }(\mathrm{pH} 7.0)\end{array}$ & $\begin{array}{l}\text { Removal yield of } \\
\text { neutralization [\%] }\end{array}$ \\
\hline Al & 1941.00 & 0.90 & 99.95 \\
\hline $\mathrm{Pb}$ & 6.98 & 0.07 & 98.94 \\
\hline $\mathrm{Cu}$ & 4.92 & 0.17 & 96.57 \\
\hline $\mathrm{Zn}$ & 2.07 & 0.17 & 91.74 \\
\hline $\mathrm{Fe}$ & 0.45 & 0.07 & 85.49 \\
\hline
\end{tabular}

The best results were reached at $\mathrm{pH}$ value around the neutrality. The concentration of pollutants before and after neutralization with $\mathrm{H}_{2} \mathrm{SO}_{4}$ solution are reported in Table 1.

As it can be seen, the removal rate was very high for the main contaminants in the wastewater: $99.95 \%$ for $\mathrm{Al}$ and 98.94\% for $\mathrm{Pb}$.

\subsection{Innovative glass application}

For the purpose of glass reuse for sustainable building materials production, different glass fractions were characterized in terms of physical properties (e.g. particle size distribution, density, water absorption, fineness). Based on the measured properties several sustainable mortars and concretes formulations, incorporating reused glass for partial replacement of aggregates or cements, were designed and produced. The use of recycled glass as partial replacement of aggregates seemed promising for these materials. Mortars and concretes were tested evaluating technical performance such as density, consistency on fresh state as well as mechanical properties development at different curing stages (Figure 9). In an industrial perspective, the performance of these building materials have been assessed, referring to technical standards prescriptions, for specific construction products (e.g. masonry mortars, concretes for prefabrication). A bedding mortar of class $M_{5}$ has been produced, having similar physical-mechanical performance of mortars available on the market. Concretes with consistency up to class S5 and compressive strength $61 \mathrm{MPa}$ have been produced and implemented in the industrial plant. In total four predalles slabs, with dimensions $1.2 \mathrm{~m} \times 2.4 \mathrm{~m}$ and $1.2 \times 6.0$ $\mathrm{m}$, were manufactured and the structural check confirmed performance similar to other conventional slabs produced for the market.

\section{CONCLUSIONS}

During the ReSiEILP project a pilot plant was designed and built by the group of metallurgy of Padova University. The tests showed that the materials contained in PV waste can be recovered with high efficiency and purity. Moreover, a hydrometallurgical process was developed by ENEA for the wastewater treatment in order to make the new plant zero waste. Concerning the PV glass reuse for building materials production, sustainable mortar and concrete formulations incorporating reused glass fractions were studied and produced by CETMA and ITO. The performance of these formulations was assessed for specific construction applications (prefabricated components) and seemed comparable with commercial products.

\section{AKNOWLED GEMENTS}

This activity has received funding from the European Institute of Innovation and Technology (EIT), a body of the European Union, under the Horizon 2020, the EU Framework Programme for Research and Innovation.

\section{REFERENCES}

Choi, J., \& Fthenakis, V. (2010). Design and optimization of photovoltaics recycling infrastructure. Environ. Sci. Technol., 44, 8678-8683. https://doi.org/10.1021/es101710g

Dias, P. R., Benevit, M. G., \& Veit, H. M. (2016). Photovoltaic solar panels of crystalline silicon: Characterization and separation. Waste Manag. Res., 34(3), 235-245. https://doi.org/10.1177/0734242X 15622812
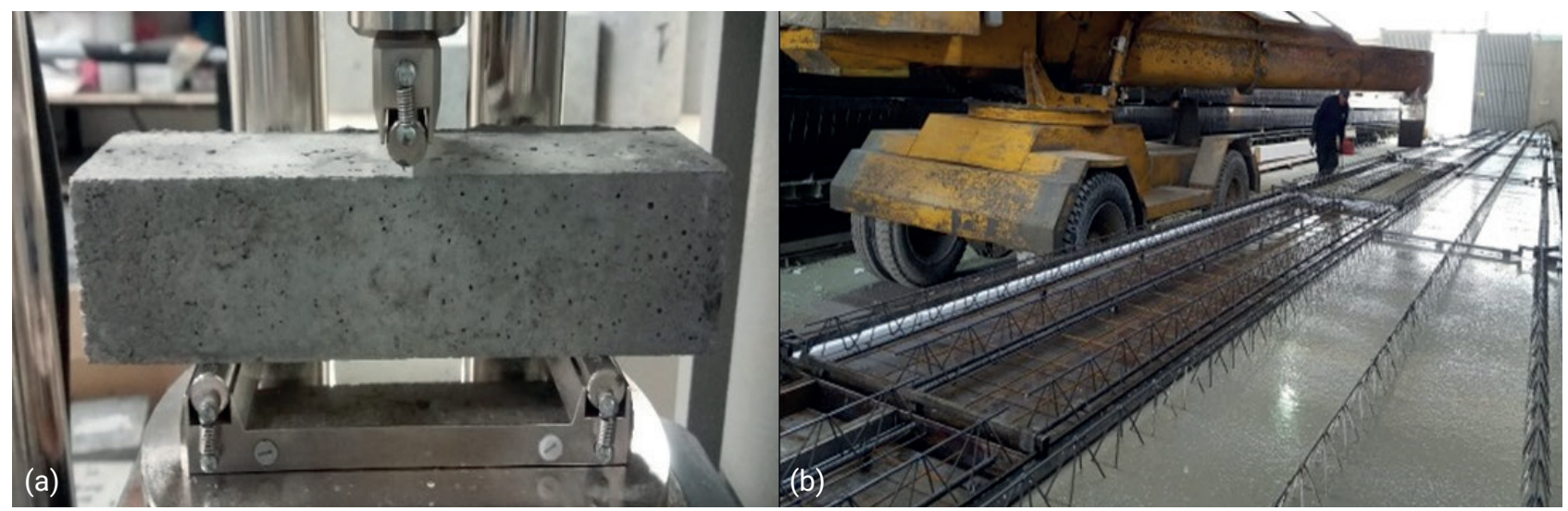

FIGURE 9: Building materials with glass from PV-panels: mechanical test on mortar (a) and industrial production of concrete (b). 
European Commision, (2015). Report on critical raw materials for EU. Jäger-Waldau, A. (2017). PV Status Report 2017.

Korjakins, A., Shakhmenko, G., Bajare, D., \& Bumanis, G. (2012). Effect of ground glass fineness on physical and mechanical properties of concrete. Proceedings of the 10th International Congress for Applied Mineralogy (ICAM) (pp. 395-402). Berlin: Springer. https:// doi.org/10.1007/978-3-642-27682-8_47

Müller, A., Wambach, K., \& Alsema, E. (2006). Life Cycle Analysis of Solar Module Recycling Process. Mater. Res. Soc. Symp. Proc. (p. 895). Materials Research Society.

Paiano, A. (2015). Photovoltaic waste assessment in Italy. Renew. Sust. Energ. Rev., 41, 99-112. https://doi.org/10.1016/j.rser.2014.07.208

Sgarioto, S., Cerchier, P., Brunelli, K., Pezzato, L., Dabala, M., Tammaro M., . . . Rakotoniaina, J. (2018). ReSiELP: Recovery of Silicon and other materials from End-of-Life Photovoltaic Panels. Proceedings of SUM2018. Bergamo.
Tamanna, N., Mohamed Sutan, N., Lee, D., \& Yakub, I. (2013). Utilization of waste glass in concrete. chez 6th International Engineering conference, Energy and Environment (ENCON) (pp. 323-329). At Kuching: Research Publishing. https://doi.org/10.3850/978-98107-6059-5_090

IRENA and IEA-PVPS (2016), End-of-Life Management: Solar Photovoltaic Panels. International Renewable

Energy Agency and International Energy Agency Photovoltaic Power Systems.

Xu, Y., Li, J., Tan, Q., Peters, A. L., \& Yang, C. (2018). Global status of recycling waste solar panels: A review. J. Waste Manag., 75, 450458. https://doi.org/10.1016/j.wasman.2018.01.036 